\title{
8-oxo-7,8-dihydro-2'-deoxyguanosine as a biomarker of oxidative damage in oesophageal cancer patients: lack of association with antioxidant vitamins and polymorphism of hOGG1 and GST
}

Stéphanie Lagadu', Mathilde Lechevrel ${ }^{1,2}$, François Sichel ${ }^{1}$, Jean Breton ${ }^{3}$, Didier Pottier ${ }^{1}$, Rémy Couderc ${ }^{4}$, Fathi Moussa ${ }^{4}$, Virginie Prevost ${ }^{1 *}$

\begin{abstract}
Background: The present report was designed to investigate the origins of elevated oxidative stress measured in cancer patients in our previous work related to a case-control study (17 cases, 43 controls) on oesophageal cancers. The aim was to characterize the relationship between the levels of 8-oxo-7,8-dihydro-2'-deoxyguanosine (8-oxodG), antioxidant vitamins and genetic susceptibility.

Methods: 8-oxodG was analysed in peripheral blood mononuclear cells (PBMCs) by High Performance Liquid Chromatography with Electrochemical Detection (HPLC-ED). Analysis of gene polymorphisms in GSTM1 and GSTT1 was performed by multiplex PCR and in GSTP1 and hOGG1 by a PCR-RFLP method. Reversed-phase HPLC with UV detection at $294 \mathrm{~nm}$ was used to measure vitamins $A$ and $E$ in serum from the same blood samples.

Results: We observed that in our combined population (cases and control, $n=60$ ), there was no statistically significant correlation between the levels of 8-oxodG and (i) the serum concentration of antioxidant vitamins, vitamin $\mathrm{A}(P=0.290)$ or vitamin $\mathrm{E}(P=0.813)$, or (ii) the incidence of the Ser326Cys polymorphic variant $(P=0.637)$ of the hOGG1 gene. Also, the levels of 8-oxodG were not significantly associated with polymorphisms in metabolite-detoxifying genes, such as GSTs, except for the positive correlation with ValNal GST P1 allele ( $P<$ 0.0001).

Conclusions: The weakness of our cohort size notwithstanding, vitamins levels in serum and genetic polymorphisms in the hOGG1 or GST genes do not appear to be important modulators of 8-oxodG levels.
\end{abstract}

\section{Background}

Oesophageal cancer remains an important public health concern worldwide with an estimated burden of 500, 000 new cases in 2005 [1]. The two major histological types of oesophageal cancers, squamous cell carcinoma (SCC) and adenocarcinoma (ADC) differ substantially in their underlying patterns of incidence and key etiologic

\footnotetext{
* Correspondence: virginie.prevost@unicaen.fr

'Groupe Régional d'Etudes sur le Cancer - UPRES EA 1772 - IFR 146, Université de Caen - Basse-Normandie and Centre de Lutte Contre le Cancer François Baclesse, Caen, France

Full list of author information is available at the end of the article
}

factors. Alcoholism and smoking are the major established risk factors for SCC, whereas Barrett's oesophagus or gastro-oesophageal reflux disease (GORD) are consistently associated with an increased risk of ADC.

Oxidative stress and reactive oxygen species (ROS) are thought to play a role in oesophageal carcinogenesis. ROS may result from external factors such as smoking, and alcohol metabolism, or may be produced endogenously via inflammatory conditions such as oesophagitis or GORD or may also be due to precancerous lesions (Barrett's oesophagus), as has been shown experimentally in rats $[2,3]$. Diet influences incidence of 
oesophageal cancers. An adequate diet of fruits and vegetables is associated with a decreased incidence [4], presumably due to a better supply of antioxidants.

Among the various markers of oxidative stress, 8-oxo7,8-dihydro-2'-deoxyguanosine (8-oxodG) is particularly popular. It is generated by the oxidation of DNA under physiopathological conditions or environmental stress, but is also a by-product of normal cellular metabolism. It is a premutagenic oxidized-DNA lesion as it is able to mispair with adenine, thus generating $\mathrm{G}: \mathrm{C}$ to $\mathrm{T}$ :A transversion mutations, unless the lesion is repaired prior to DNA replication [5]. Moreover, affordable analytical methods are available for its quantification. In population studies, 8-oxodG is often determined in DNA extracted from white blood cells, peripheral blood mononuclear cells (PBMC) or lymphocytes, although PBMCs being mostly lymphocytes, the distinction is rarely made. These cells are considered to be representative of the whole organism in terms of the level of exposure of to oxidative stress. However, it has been suggested that the apparent high levels of 8-oxodG could be due to artefactual oxidation of DNA during the treatment of the samples. The European Standards Committee on Oxidative DNA Damage (ESCODD) has now been set up within the European laboratory network to improve and harmonise 8-oxodG measurement methods [6-9].

In a previous study [10], we have described the optimisation of an analytical procedure to measure 8-oxodG in PBMCs by using HPLC coupled with electrochemical detection (HPLC-ED). In that study [10], the protocol was applied to the analysis of 8-oxodG in PBMCs of subjects $(\mathrm{n}=60)$ from a case-control study that included both, SCC and ADC cases. Control samples (n $=43$ ) exhibited $4.9 \pm 1.9$ molecules of 8 -oxodG per $10^{6}$ unaltered guanosines, levels which correspond to the median values reported by the latest ESCODD trial for HPLC measurement in lymphocytes from healthy young men [11]. In comparison, oesophageal cancer patients (n $=17$ ) showed higher oxidative DNA damage as indicated by the 8 -oxodG levels of $7.2 \pm 2.6$ per $10^{6}, 2^{\prime}$-dG (Student's t-test, $P<0.001$ ). This difference remained significant even after technical (storage, sampling period, 2'-dG levels) and individual (age, sex, smoking, alcohol) confounding factors were taken into account $(P<$ 0.0001 , generalized linear regression model). Moreover, data on smoking habits and alcohol consumption of the volunteers were available, and could be correlated with the observed levels of oxidatively-damaged DNA.

The aim of the present study was to characterize the relationship between the levels of oxidative stress, antioxidant vitamins and genetic constitution in oesophageal cancers. An elevated level of oxidative DNA lesions could be related to exogenous or endogenous parameters. Therefore, factors that may influence the extent of oxidative DNA damage such as the nutritional status and genetic polymorphisms were included in this study.

Antioxidant vitamins, such as vitamin A and vitamin $\mathrm{E}$ are effective free radical scavengers and can also be useful markers of antioxidant status. Presumably, a higher production of ROS due to severe oxidative stress, characteristic of oesophageal cancers, could lead to a higher metabolic consumption of the antioxidant vitamins, and this would be reflected in their lower serum levels. This "antioxidant hypothesis" was examined in the subjects included in our study by determining the serum concentrations of vitamins $\mathrm{A}$ and $\mathrm{E}$.

Oxidatively damaged bases in DNA are preferentially repaired by base excision enzymes. The hOGG1 gene encodes the human 8-oxo-guanine DNA glycosylase that cleaves the 8-oxo-guanine base from damaged DNA. The single-nucleotide polymorphism at codon 326 (Ser326, rs 1052133) is the most well-studied polymorphism of $h O G G 1$. Homozygous carriers of the variant form of the hOGG1 Ser326Cys gene appear to have a reduced capacity to repair oxidised DNA lesions [12-14], although this is controversial [15]. A genetic susceptibility toward SCC of the oesophagus linked to the Ser326Cys polymorphism in the hOGG1 gene has been described [16]. We have measured this polymorphism in our population and correlated it with the corresponding 8-oxodG level.

Polymorphism also exists in genes encoding enzymes involved in the metabolism of xenobiotics that act as an indirect source of free radicals. Genetic polymorphisms in genes involved in detoxification such as glutathioneS-transferases (GST), GSTM1, GSTT1 and GSTP1 could potentially affect the susceptibility of an individual to the adverse effects of environmental risk factors involved in oesophageal cancer. The above three genes, are expressed in the oesophageal mucosa. We have earlier reported a significant increase in the risk of oesophageal cancers correlated with the null genotypes of GSTM1 and GSTT1 but not with the GSTP1 Ile/Val polymorphism [17]. The polymorphisms in the GST genes were analysed according to their histological status, among controls and cases of oesophageal cancers. These polymorphisms were revisited in the present study to investigate their correlation with the levels of 8-oxodG.

\section{Methods}

\section{Patients and controls}

Following an approval from the ethical committee (Comité Consultatif pour la Protection des Personnes en Recherche Biomédicale, Basse-Normandie), consenting patients and control subjects were recruited between 1996 and 2000 within the context of a case-control 
study aimed at identification of various biomarkers suitable for molecular epidemiology of oesophageal cancers [17]. The control group $(n=43)$ included healthy donors, who had no clinical history of chronic diseases or cancer and were living in the Lower Normandy, France. Seventeen oesophageal cancer patients from the University Hospital of Caen, France, were selected based on the availability of biological samples. Diagnosis was performed at the Department of Hepato-gastroenterology, University Hospital of Caen, France, and the Department of Anatomopathology, François Baclesse Center, Caen, France. Out of the 17 patients, 9 presented with SCC, 7 with ADC and 1 with leiomyoma, a rare histological subtype. All cases were newly diagnosed and previously untreated. Individual data related to age, sex, alcohol consumption and smoking habits of the subjects have been published earlier [10] and are summarized in Table 1 . Twenty $\mathrm{ml}$ of venous blood samples were collected before performing any procedure such as surgery, radio- or chemotherapy. The PBMCs were separated and used for quantification of 8-oxodG and genetic polymorphisms from blood samples of all individuals $(n=60)$, while the serum was used for quantification of the vitamins $A$ and $E$ from all except three samples $(\mathrm{n}=57)$, for which the volumes were insufficient.

\section{PBMC collection, DNA isolation and hydrolysis}

Care was taken to avoid artefactual oxidation of DNA during its extraction and hydrolysis. PBMCs were isolated from $12 \mathrm{ml}$ out of the $20 \mathrm{ml}$ blood samples using Unisep Maxi tubes (Novamed). These were stored in liquid nitrogen until being used for DNA isolation. Latter was performed using the "protocol G" described by Ravanat et al. [18] with modifications aimed at optimisation of the analytical procedure with minimum delays [10]. Other modifications included addition of desferrioxamine to extraction and digestion buffers.

\section{8-oxodG HPLC-ED analysis}

An optimised method for the quantification of 8-oxodG in PBMCs has been described previously [10]. Briefly, the DNA hydrolysate was analysed by HPLC with an electrochemical detector (Coulochem II; ESA Inc., Chelmsford, MA) using a Supelcosil reversed-phase C18

Table 1 Description of individual data

\begin{tabular}{ccc}
\hline Parameter & Controls (43) & Patients (17) \\
\hline Age (years) & $64 \pm 8$ & $63 \pm 9$ \\
Sex men/women & $27 / 16$ & $14 / 3$ \\
Smoking (cigarettes per week) & $52 \pm 79^{\mathrm{a}}$ & $113 \pm 97^{\mathrm{b}}$ \\
Alcohol (grams/week) & $143 \pm 140^{\mathrm{a}}$ & $289 \pm 258^{\mathrm{b}}$ \\
\hline
\end{tabular}

Numbers represent values for mean \pm standard deviation; $^{\mathrm{a}}: \mathrm{n}=36^{\mathrm{b}}: \mathrm{n}=10$.
HPLC column $(150 \times 3 \mathrm{~mm}, 5 \mu \mathrm{m}$-Supelco $)$ equipped with a $\mathrm{C} 18$ guard column. The eluant was $10 \mathrm{mM}$ potassium dihydrogen phosphate, $\mathrm{pH} 4.6$, containing $7.5 \%$ methanol, at a flow rate of $0.6 \mathrm{ml} / \mathrm{min}$. The potentials applied to the analytical cell (ESA 5011) were +50 $\mathrm{mV}$ and $+350 \mathrm{mV}$ for E1 and E2, respectively. 2'dG was measured in the same run of corresponding 8-oxodG with a UV detector (Pharmacia LKB VWM 2141) at 290 $\mathrm{nm}$ situated after the ED cell. Acquisition and quantitative analyses of chromatograms were carried out using Eurochrom 2000 software (Knauer). The amount of 8oxodG in DNA was calculated as the number of 8 oxodG molecules $/ 10^{6}$ unmodified 2'dG.

\section{HPLC determination of serum vitamin $A$ and $E$}

Concentrations of vitamins $A$ and $E$ were measured in the sera obtained from the blood samples of all subjects, except for 3 (1 control, 2 patients). The serum fraction was obtained after the isolation of PBMCs from blood by centrifugation at $1000 \times g$ for $20 \mathrm{~min}$. Samples from control and cancer subjects were stored in the same conditions, at $-80^{\circ} \mathrm{C}$ for several years until analysis.

Simultaneous determination of vitamin $\mathrm{A}$ and $\mathrm{E}$ was performed by HPLC as previously described [19], with the following modifications. The HPLC system consisted of a Summit Dual Gradient System including a diode array detector from Dionex (Voisin le Bretonneux, France). The stationary phase consisted of a LiChroCART $^{\circ}$ 125-4 LiChrospher 100 RP-18, $5 \mu$ m protected by a guard column filled with the same stationary phase both from Merck Chemicals, France. The mobile phase consisted of methanol and the flow rate was $0.8 \mathrm{ml} / \mathrm{min}$. Separations were carried out at $25^{\circ} \mathrm{C}$. Vitamin A and $\mathrm{E}$ peaks were integrated at $294 \mathrm{~nm}$ and the specificity of the detection was based on retention factors and comparison of UV-Visible spectra with those collected from the standard samples. For the calibration of the method and for quality control we used lyophilised standard and quality control serums from RECIPE (Munich, Germany). $100 \mu \mathrm{L}$ of samples of either serum or a standard solution or quality control sample, were added to 200 $\mu \mathrm{L}$ of a solution of ethanol containing tocopheryl acetate $(4 \mu \mathrm{M})$ that was used as an internal standard. After stirring the mixture for 30 seconds, the vitamins were extracted with $1000 \mu \mathrm{L}$ of hexane (2 min of stirring). The organic phase was evaporated under nitrogen and the residues dissolved in $200 \mu \mathrm{L}$ of methanol and $50 \mu \mathrm{L}$ were injected into the chromatograph. All procedures were performed in a room with glass windows that prevented penetration of direct sunlight.

\section{GSTM1, GSTP1, GSTT1 and hOGG1 genotyping analysis}

DNA was extracted by the phenol-chloroform method using an aliquot out of the $20 \mathrm{ml}$ venous blood samples 
of the subjects. Determination of GSTM1, GSTP1 and GSTT1 polymorphisms in the 60 subjects was performed as previously described [17]. Analysis of deletion polymorphism in GSTM1 and GSTT1 was performed by multiplex PCR and that of single nucleotide polymorphism in GSTP1by a PCR-RFLP method as previously described [20]. In addition to these polymorphisms, subjects were also genotyped for the presence of either the serine or cysteine codon at position 326 (rs 1052133) of the hOGG1 gene by PCR-RFLP, using primers and conditions as previously described [21]. Briefly, the PCR amplification of the $293 \mathrm{bp}$ fragment consisted of a 15min denaturation at $95^{\circ} \mathrm{C}$ followed by 30 cycles of $95^{\circ} \mathrm{C}$ for $1 \mathrm{~min}, 50^{\circ} \mathrm{C}$ for $1 \mathrm{~min}$ and $72^{\circ} \mathrm{C}$ for $1 \mathrm{~min}$. A final extension step of $72^{\circ} \mathrm{C}$ for $10 \mathrm{~min}$ was included. We used a simple RFLP method to identify the Ser326Cys by virtue of an Fnu4HI restriction site. The hOGG1 PCR product was digested with $F n u 4 \mathrm{HI}$ overnight at $37^{\circ}$ C. Recovery of two digested fragments $(123 / 124 \mathrm{bp}$ and $169 / 170 \mathrm{bp}$ ) indicated presence of the Cys326 allele, while an undigested amplicon indicated the Ser326 allele.

\section{Statistical analysis}

All statistics and graphics have been performed with the SAS System release 9 (SAS Institute Inc., Cary, NC, USA). Distributions of 8-oxodG were normalised by logarithmic transformations. Mean values were compared by Student's t-test or ANOVA and correlations between 8-oxodG and antioxidants were evaluated by Pearson correlation test. All statistical analyses were two-sided.

\section{Results}

\section{Blood levels of 8-oxodG and vitamins $A$ and $E$}

The mean serum concentrations of vitamin A were 2.77 $\mu \mathrm{M}$ and $2.74 \mu \mathrm{M}$, while those for vitamin $\mathrm{E}$ were 34.77 $\mu \mathrm{M}$ and $38.73 \mu \mathrm{M}$, in patients and controls respectively (Table 2).

There was a high intersample variability in the levels of vitamins across subjects, as indicated by the wide range of values. The mean values in the subjects were in the range of values reported recently by others for these vitamins [22-25]. There were no significant differences in the levels of vitamins $\mathrm{A}$ and $\mathrm{E}$ between the control and cases. Further, there was no significant correlation found between the levels of 8-oxodG and those of vita$\min \mathrm{A}(\mathrm{R}=0.1425 ; P=0.290)$ or vitamin $\mathrm{E}(\mathrm{R}=0.0321$; $P=0.813)$ when cases and controls were combined (Pearson correlation test, two-sided). However, a positive correlation between the levels of 8-oxodG and vita$\min \mathrm{A}(\mathrm{R}=0.5714 ; P=0.026)$ and vitamin $\mathrm{E}(\mathrm{R}=$ $0.4834 ; P=0.068)$ was observed when only cases $(\mathrm{n}=$ 17) were taken into account (Figure 1).

\section{Levels of 8-oxodG and hOGG1 polymorphism}

The potential relationship between 8-oxodG and the Ser326Cys polymorphism in the hOGG1 gene was examined in the pooled population of cases and controls. Comparisons of means of 8-oxodG between genotypes were done with ANOVA after logarithmic transformation. As shown in Figure 2, there was no statistically significant association between levels of 8-oxodG in DNA and hOGG1 Ser326Cys polymorphism $(P=0.637)$. The prevalence of the Cys allele, $h O G G 1^{326 C y s}$, was 0.27 in the controls and 0.09 in the cases (Table 3).

\section{Levels of 8-oxodG and frequency of GST alleles}

The level of 8-oxodG according to GST polymorphisms was examined in the pooled population after logarithmic transformation. There was no difference with the null genotypes of the GSTM1 (Student $\mathrm{t}$ test; $P=0.982$ ), and GSTT1 (Student $\mathrm{t}$ test; $P=0.345$ ), whereas there was a strong difference between GSTP1 variants (ANOVA, $P$ $<0.0001$ ) (Figure 3).

\section{Discussion}

Oxidative damage to DNA is considered to be an important risk factor for carcinogenesis. 8-oxodG is a key biomarker in this process because it is one of the most frequently encountered product of oxidativelydamaged DNA and also one that can be easily detected in samples of tissues or urine [26-30]. We have previously reported a significantly higher level of 8-oxodG in circulating blood cells from oesophageal cancer patients compared to control subjects [10]. Similar observations have been made for colorectal carcinoma [31], lung cancer $[22,24,32]$ and leukaemia [33,34]. In

Table 2 Biochemical parameters of the study group

\begin{tabular}{lccc}
\hline Parameter & Patients (mean \pm s.d.) & Controls (mean \pm s.d.) & $\begin{array}{c}\text { P-value } \\
\text { patient vs. control }\end{array}$ \\
\hline 8-oxodG $/ \mathbf{1 0}^{\mathbf{6}} \mathbf{2}^{\mathbf{\prime}} \mathbf{d G} \mathbf{C}^{\mathrm{c}}$ & $7.2 \pm 2.6(n=17)$ & $4.9 \pm 1.9(n=43)$ & $P<0.001$ \\
Vitamin A $(\boldsymbol{\mu M})$ & $2.77 \pm 0.94(n=15)^{\mathrm{a}}$ & $2.74 \pm 0.61(n=42)^{\mathrm{a}}$ & $P=0.895$ \\
Vitamin E $(\boldsymbol{\mu M})$ & $34.77 \pm 12.27(n=15)^{\mathrm{a}}$ & $38.73 \pm 9.47(n=42)^{\mathrm{a}}$ & $P=0.204$ \\
\hline
\end{tabular}

PBMCs were collected and processed for measuring 8-oxodG. Vitamins were extracted from the serum samples for estimation. ${ }^{a}$ Numbers in parentheses indicate the number of samples analysed as some samples had to be omitted due to insufficient volume of serum collected. A total of 57 out of the 60 samples were

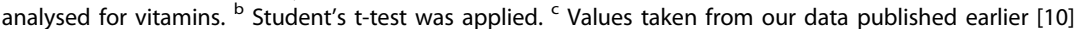


(a)

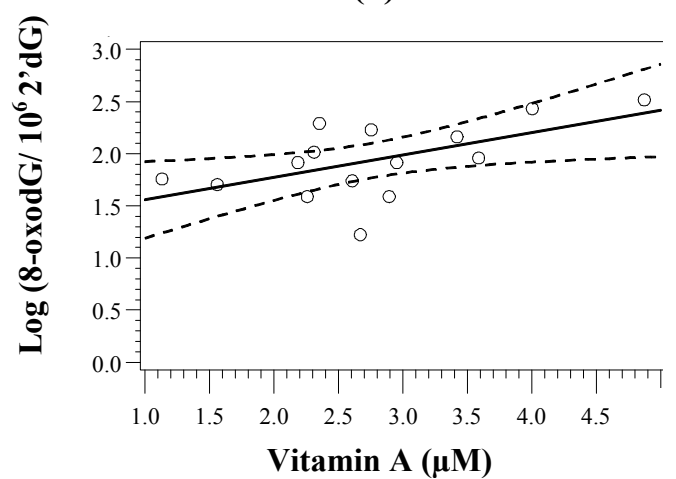

(b)

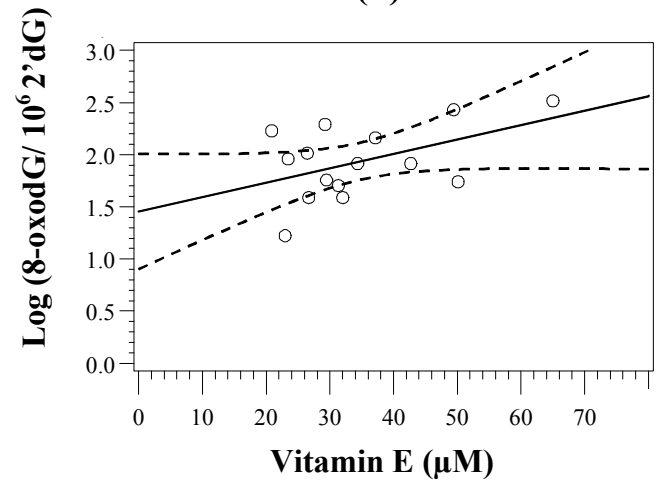

Figure 1 Correlation between 8-oxodG levels and vitamin A (a) and vitamin $\mathbf{E}$ (b) in cancer patients group ( $\mathbf{n}=\mathbf{1 5}$ ). 8-oxodG level is expressed as the number of molecules of 8-oxodG per $10^{6} 2^{\prime} \mathrm{dG} ; \mathrm{R}=0.5714$ and $P=0.026$ for correlation between 8 -oxodG and vitamin $A$; and $\mathrm{R}=0.4834$ and $P=0.068$ for correlation between 8-oxodG and vitamin $\mathrm{E}$; Log of 8-oxodG (Y-axis) is plotted against vitamin $\mathrm{A}$ and $\mathrm{E}$ concentrations as indicated; circles, values for individual data; full line, linear regression; dotted line, 95\% confidence limit.

our study, none of the individual variables such as smoking, alcohol, sex or age, was shown to influence 8oxodG concentrations. The aim of the present study was to identify other factors that could modulate 8oxodG levels. We have attempted to characterize the relationship between oxidative stress, evaluated in terms of levels of 8-oxodG in PBMCs, and the levels of antioxidant vitamins and the genetic constitution, in a population consisting of healthy volunteers and oesophageal cancer patients.

Vitamin C, vitamin E, carotenoids, and other antioxidants present in fruits and vegetables could contribute to cancer prevention by protecting DNA from oxidative damage, according to the "antioxidant hypothesis". By inference, the endogenous levels of these antioxidant vitamins in the serum of oesophageal cancer patients are expected to be low. Likewise, under conditions of severe oxidative stress also, their serum levels may be low as these would be consumed in redox reactions involving ROS.

Many recent epidemiological studies have confirmed that a high intake of fruits and vegetables is associated with a decreased risk of upper aero-digestive tract cancers [4,35-37]. One of the possible mechanisms of this protective effect is the antioxidant activity of vitamins A, $\mathrm{C}$ and $\mathrm{E}$. These vitamins are effective antioxidants in vitro, and might be expected to protect against cancer. Calişkan-Can et al. [24] found lower levels of $\beta$-carotene and vitamins $\mathrm{A}, \mathrm{C}$ and $\mathrm{E}$ in lung cancer patients compared to healthy controls. Foksinski et al. [23] observed that the mean levels of all the measured antioxidant vitamins were significantly lower in smokers in

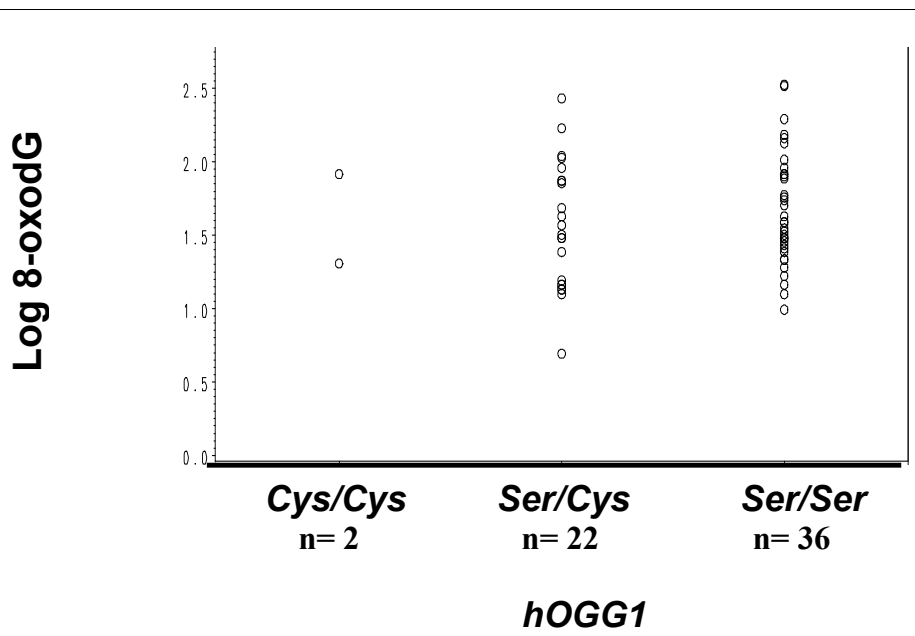

Figure 2 Levels of 8-oxodG according to hOGG1 genotypes. Data from patients and controls were combined $(n=60)$ and analyzed by ANOVA ( $P=0.637$ ). 8-oxodG level is expressed as the number of molecules of 8-oxodG per $10^{6} 2^{\prime} \mathrm{dG}$ and Log of 8-oxodG (Y-axis) is plotted against frequencies of hOGG1 genotypes as indicated. circles, values of individual sample. 
Table 3 Genotype frequency of hOGG1 Ser326Cys in patients with oesophageal cancer

\begin{tabular}{cccc}
\hline Genotype & $\begin{array}{c}\text { Controls }(\mathbf{n}= \\
\mathbf{4 3}) \\
\mathbf{( \% )}\end{array}$ & $\begin{array}{c}\text { Patients }(\mathbf{n}= \\
\mathbf{1 7})\end{array}$ & $\begin{array}{c}\text { Total }(\mathbf{n}= \\
\mathbf{6 0})\end{array}$ \\
\hline Ser/Ser & $22(51)$ & $14(82)$ & $36(60)$ \\
Ser/Cys & $19(44)$ & $3(18)$ & $22(37)$ \\
Cys/Cys & $2(5)$ & 0 & $2(3)$ \\
\hline $\begin{array}{c}\text { Cys allele } \\
\text { frequency }\end{array}$ & 0.27 & 0.09 & 0.22
\end{tabular}

Numbers in parentheses represent the relative percentage in the group.

comparison with non-smokers. Gackowski et al. [22] reported that vitamin E levels were significantly reduced in the plasma of lung cancer patients (smokers and exsmokers) compared to healthy smokers and that the levels of vitamins A and E in plasma of colorectal carcinoma patients were lower than in the control group [31]. In contrast, other studies found no significant differences between healthy smokers and non-smokers for either serum vitamin A or vitamin E [22,38,39]. Also, several large-scale antioxidant supplementation trials have failed to show any clear evidence for a decrease in cancer risk $[30,40]$. In our study, we found that the endogenous serum levels of vitamins $\mathrm{A}$ and $\mathrm{E}$ were similar in oesophageal cancer patients and in controls. Notably, despite the fact that our study subjects come from the same geographical area, there was substantial intersample variability, especially for the cancer cases. These differences could reflect the balance between absorption and tissue secretion, and may also be genetically determined. A recording of dietary habits (fruit and vegetable consumption) could have added a complementary and an interesting feature to our study. Determination of the two major water-soluble antioxidants, ascorbate and glutathione would also have brought complementary information. However, as particular conditions are required for sample collection, processing and storage to prevent their oxidation and degradation, these could not be analysed in this retrospective study.

Correlation between the levels of vitamins and 8oxodG has been reported. In their analyses of 30 crosssectional studies, Moller \& Loft [41] identified 12 studies showing an inverse correlation between oxidatively damaged DNA and antioxidant levels, 16 reporting no correlation and two, a positive correlation. A lack of a correlation between 8-oxodG and antioxidant vitamins has also been reported by others $[22,35,42]$. In a recent paper, Sram et al. [43] found a negative correlation between 8-oxodG and $\beta$-carotene and vitamin $E$ but a weak positive association with vitamin A. Similar positive correlations were reported for vitamin A in chemical workers exposed to vinyl chloride monomer [44], carotenoids and vitamin E [45]. We did not find any correlation between the levels of 8-oxodG and vitamins in our study group (cases and controls combined).

Interpretation of these correlative data must be made with extreme caution because the precise effects of antioxidants on mutagenesis and carcinogenesis remain unclear. An antioxidant, including a vitamin antioxidant, is essentially a redox (reduction-oxidation) agent that provides protection against free radicals, but may promote free radical generation under certain circumstances or may exert pro-oxidant effects. Conversely, recent meta-analysis on supplementation trials indicates increased risk of mortality [40], suggesting a pro-oxidant activity at high doses or in cancer-risk subjects (smokers and workers exposed to asbestos). Further, besides

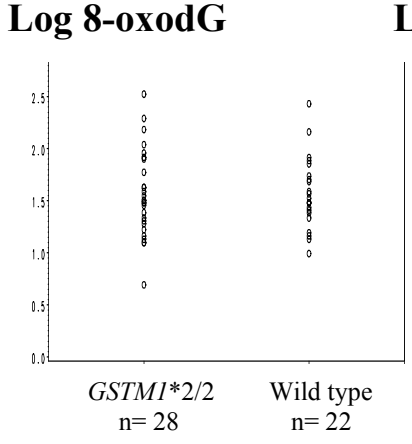

GSTM1
Log 8-oxodG

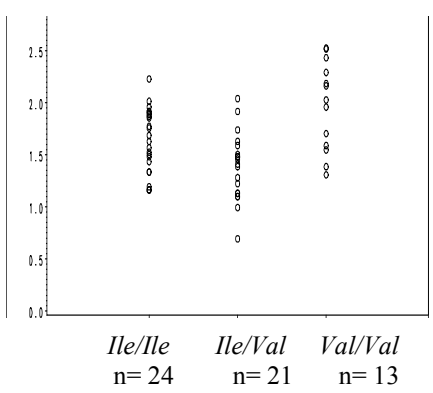

GSTP1

\section{Log 8-oxodG}

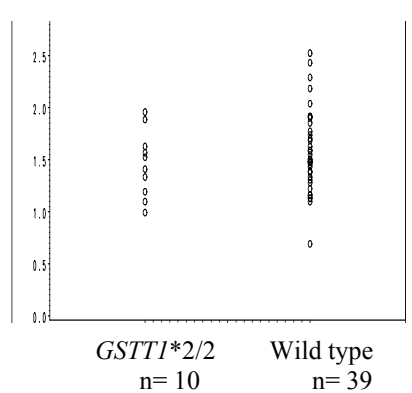

GSTT1

Figure 3 Levels of 8-oxodG according to genotypes of GSTM1, GSTP1 and GSTT1. Data from patients and controls were combined ( $\mathrm{n}=$ 60). 8-oxodG level is expressed as the number of molecules of 8-oxodG per $10^{6} 2^{\prime} \mathrm{dG}$ and Log of 8-oxodG (Y-axis) is plotted against frequencies of the various genotypes as indicated, GSTM1 ( $P=0.982)$, GSTP1 ( $<0.0001$ for Val/Nal vs lle/lle and lle/Nal) and GSTT1 $(P=0.345)$; circles: values for individual data. 
vitamins, several food-derived phytochemicals or bioreactive substances in natural products likely contribute to the protection of DNA from damage and thus influence the generation of 8-oxodG in vivo. The number of such antioxidants exceeds that of antioxidant vitamins. The availability of these unidentified antioxidants in individual diet could thus affect the correlation between levels of 8-oxodG and antioxidant vitamins. Some dietary components also could up-regulate DNA repair without having any recognised antioxidant function. Interestingly, a positive association was observed in our study between the levels of 8-oxodG and those of the two vitamins, but only in the cases and not in the controls. However, this observation should be interpreted with caution, in the light of the foregoing discussion. Moreover, to arrive at a more convincing conclusion, our data would have to be expanded and adjusted for possible confounders such as age which can become the predominant, independent determinant of oxidative damage as has been discussed recently [43].

In view of the conflicting reports in the literature and the results of the present study, the "antioxidant hypothesis" seems open to criticism. Is there indeed a relationship between antioxidant vitamins and oxidativelydamaged DNA? Secondly, are the concentrations of antioxidants and 8-oxodG in the blood representative measures of the situation in the target tissue of the carcinogenesis and a true reflection of overall cellular DNA damage? Thirdly, do we have reliable tools to examine this correlation? The choice and reliability of biomarkers such as 8 -oxodG has also been debated $[28,30,46]$. The reliability of 8-oxodG is influenced by its method of detection since its artefactual production is a serious concern. Notably, the values of 8-oxodG reported in this study are low and reach the background level of 8oxodG recommended by ESCODD for HPLC-ED measurement, indicating that these were not an artefact.

It is known that individuals have different responses to oxidative damage and that the risk for oxidative stressrelated cancer varies according to both, the environmental exposure and the genetic background. The human 8oxoguanine DNA glycosylase1 (hOGG1) is one of the major enzymes involved in DNA base excision repair (BER). A positive relationship between hOGG1 mRNA expression and 8-oxodG suggests that the expression level of hOGG1 may be interpreted as a biomarker of exposure to oxidative DNA damage $[47,48]$. On the other hand, some studies indicated that there was no interaction between these parameters $[12,49,50]$, which could be explained by the fact that $h O G G 1$ is weakly expressed in certain tissues such as the aerodigestive tract tissue [51].

The activity of hOGG1 can be impaired by a polymorphic mutation at codon 326, the hOGG1 Ser326Cys polymorphism. However, the phenotypic impact of hOGG1 Ser326Cys polymorphism is unclear. Recent data have shown that the hOGG1 Ser326Cys polymorphism is associated with a reduced DNA repair capacity for oxidatively-damaged DNA [52], whereas according to others, the converse is true $[15,53,54]$. This led to the conclusion that both, wild type and the hOGG1Cys326 variant-encoded proteins should be functional and probably do not exhibit significant differences in repair activities and hence the polymorphism at codon 326 would probably be neutral $[53,55]$.

Many epidemiological studies have investigated the association of the Ser326Cys polymorphism in the hOGG1 gene indicating an increased risk for head and neck cancers but the reports are conflicting $[51,56,57]$. Studies on the prevalence of this polymorphism in susceptibility to oesophageal cancer also show conflicting results. Xing et al. [16] reported a positive association between the Cys326 variant and oesophageal cancer risk in Asians population whereas Tse et al. [58] reported no association in Caucasians. In the present study, the small number of samples did not allow us to make a comparison of the genotype distribution between cases and controls in order to determine whether the $h O G G 1^{326 C y s}$ allele contributed to the risk of oesophageal cancer. However, the distribution of hOGG1 Ser326Cys genotype in our controls (0.44) is in agreement with the frequencies previously described in Caucasian population. This frequency is classically lower than that in Asians [21,51,59], suggesting that this allele may be differently distributed among ethnic groups and may not confer a particular susceptibility to oesophageal cancer in Caucasian population. The allelic distribution of this polymorphism in our combined population followed Hardy-Weinberg equilibrium.

Besides DNA repair activity, enzymes involved in the detoxification of xenobiotics such as glutathione $S$-transferases may influence the extent of oxidative damage in humans. We genotyped our study population for the GSTM1, GSTT1 and GSTP1 genes. Our results indicate no association between GSTM1 and GSTT1 null polymorphisms and 8-oxodG levels in DNA from PBMCs. On the other hand, we found a statistically significant association between GSTP1 Val/ $\mathrm{Val}$ homozygote carriers and a high level of 8-oxodG (Figure 2). However, as no obvious relationship was found between the frequency of the $\mathrm{Val}$ allele $(\mathrm{Val} / \mathrm{Val}$ and Ile/Val combined) and the level of 8-oxodG, we consider this result questionable. Indeed, correlation of GST polymorphisms with 8-oxodG levels in WBCs or lymphocytes varies with the context of exposure: polycyclic aromatic hydrocarbons [60,61], benzene [62], fine particulate matters [63] and hyperbaric oxygen [64]. 


\section{Conclusions}

In conclusion, although the power of our study is limited, it seems likely that vitamin levels in serum and polymorphisms in the hOGG1 or GST genes are not important modulators of 8-oxodG levels. Further studies in a larger cohort of patients using other biomarkers of oxidative damage and antioxidant status are required to better understand the possible involvement of oxidative stress in oesophageal cancer.

\section{List of abbreviations}

ADC: adenocarcinoma (ADC); ESCODD: European Standards Committee on Oxidative DNA Damage; GST: glutathione- $S$-transferase; HPLC-ED: HPLC coupled with electrochemical detection; PBMC: peripheral blood mononuclear cells; SCC: squamous cell carcinoma; 8oxodG: 8-oxo-7,8-dihydro-2'-deoxyguanosine.

\section{Acknowledgements and funding}

This work was supported by a grant from the Ligue Nationale Contre le Cancer (Committees of Orne and La Manche). We thank Dr. Anuradha Alahari for help in writing the manuscript.

\section{Author details}

${ }^{1}$ Groupe Régional d'Etudes sur le Cancer - UPRES EA 1772 - IFR 146, Université de Caen - Basse-Normandie and Centre de Lutte Contre le Cancer François Baclesse, Caen, France. ${ }^{2}$ Laboratoire de biologie moléculaire et cellulaire de la signalisation - EA 3919 - Université de Caen-Basse Normandie, France. ${ }^{3}$ CEA Grenoble/INAC/Service de Chimie Inorganique et Biologique, UMR E3 CEA-Université Joseph Fourier, CNRS FRE3200, Laboratoire «Lésions des Acides Nucléiques » Grenoble, France. ${ }^{4}$ Service de biochimie, Hôpital Armand Trousseau, AP-HP, France.

\section{Authors' contributions}

SL: genotyping analysis of polymorphisms, data analysis; ML: interpretation of data concerning polymorphisms, critical revision for important intellectual content; FS: conception and design of the study, interpretation of data, final approval of the version to be published; JB: analysis of 8-oxodG, interpretation of data, critical reading of the manuscript; DP: statistical analysis of the data; RC: interpretation of data concerning vitamins and critical reading of the manuscript; FM: analysis of vitamins and interpretation of these data; VP: coordination of project, interpretation of data and writing of manuscript. All authors have read and approved the final manuscript.

\section{Competing interests}

The authors declare that they have no competing interests.

Received: 28 September 2010 Accepted: 6 December 2010 Published: 6 December 2010

\section{References}

1. Lambert $R$, Hainaut $P$ : The multidisciplinary management of gastrointestinal cancer. Epidemiology of oesophagogastric cancer. Best Pract Res Clin Gastroenterol 2007, 21:921-945.

2. Oh TY, Lee JS, Ahn BO, Cho H, Kim WB, Kim YB, Surh YJ, Cho SW, Hahm KB: Oxidative damages are critical in pathogenesis of reflux esophagitis: implication of antioxidants in its treatment. Free Radic Biol Med 2001, 30:905-915.

3. Lee JS, Oh TY, Ahn BO, Cho H, Kim WB, Kim YB, Surh YJ, Kim HJ, Hahm KB: Involvement of oxidative stress in experimentally induced reflux esophagitis and Barrett's esophagus: clue for the chemoprevention of esophageal carcinoma by antioxidants. Mutat Res 2001, 480-481:189-200.

4. Holmes RS, Vaughan TL: Epidemiology and pathogenesis of esophageal cancer. Semin Radiat Oncol 2007, 17:2-9.
5. Cheng KC, Cahill DS, Kasai H, Nishimura S, Loeb LA: 8-Hydroxyguanine, an abundant form of oxidative DNA damage, causes $\mathrm{G}-\mathrm{C}$ and $\mathrm{A}-\mathrm{C}$ substitutions. J Biol Chem 1992, 267:166-172.

6. ESCODD (European Standards Committee on Oxidative DNA Damage): Comparison of different methods of measuring 8-oxoguanine as a marker of oxidative DNA damage. Free Radic Res 2000, 32:333-341.

7. ESCODD (European Standards Committee on Oxidative DNA Damage): Comparative analysis of baseline 8-oxo-7,8-dihydroguanine in mammalian cell DNA, by different methods in different laboratories: an approach to consensus. Carcinogenesis 2002, 23:2129-2133.

8. ESCODD (European Standards Committee on Oxidative DNA Damage): Inter-laboratory validation of procedures for measuring 8-oxo-7,8dihydroguanine/8-oxo-7,8-dihydro-2'-deoxyguanosine in DNA. Free Radic Res 2002, 36:239-245.

9. ESCODD (European Standards Committee on Oxidative DNA Damage): Measurement of DNA oxidation in human cells by chromatographic and enzymic methods. Free Radic Biol Med 2003, 34:1089-1099.

10. Breton J, Sichel F, Pottier D, Prevost V: Measurement of 8-oxo-7,8-dihydro2 '-deoxyguanosine in peripheral blood mononuclear cells: optimisation and application to samples from a case-control study on cancers of the oesophagus and cardia. Free Radic Res 2005, 39:21-30.

11. Collins AR, Cadet J, Möller L, Poulsen HE, Viña J: Are we sure we know how to measure 8-oxo-7,8-dihydroguanine in DNA from human cells? Arch Biochem Biophys 2004, 423:57-65.

12. Kohno T, Shinmura K, Tosaka M, Tani M, Kim SR, Sugimura H, Nohmi T, Kasai H, Yokota J: Genetic polymorphisms and alternative splicing of the hOGG1 gene, that is involved in the repair of 8-hydroxyguanine in damaged DNA. Oncogene 1998, 16:3219-3225.

13. Smart DJ, Chipman JK, Hodges NJ: Activity of OGG1 variants in the repair of pro-oxidant-induced 8-oxo-2'-deoxyguanosine. DNA Repair (Amst) 2006, 5:1337-45.

14. Vodicka P, Stetina R, Polakova V, Tulupova E, Naccarati A, Vodickova L, Kumar R, Hanova M, Pardini B, Slyskova J, Musak L, De Palma G, Soucek P, Hemminki K: Association of DNA repair polymorphisms with DNA repair functional outcomes in healthy human subjects. Carcinogenesis 2007, 28:657-664.

15. Janssen K, Schlink K, Götte W, Hippler B, Kaina B, Oesch F: DNA repair activity of 8-oxoguanine DNA glycosylase 1 (OGG1) in human lymphocytes is not dependent on genetic polymorphism Ser326/ Cys326. Mutat Res 2001, 486:207-216.

16. Xing DY, Tan W, Song N, Lin DX: Ser326Cys polymorphism in hOGG1 gene and risk of esophageal cancer in a Chinese population. Int $J$ Cancer 2001, 95:40-143.

17. Abbas A, Delvinquiere K, Lechevrel M, Lebailly P, Gauduchon P, Launoy G, Sichel F: GSTM1, GSTT1, GSTP1 and CYP1A1 genetic polymorphisms and susceptibility to esophageal cancer in a French population: different pattern of squamous cell carcinoma and adenocarcinoma. World J Gastroenterol 2004, 10:3389-3393.

18. Ravanat JL, Douki T, Duez P, Gremaud E, Herbert K, Hofer T, Lasserre L, Saint-Pierre C, Favier A, Cadet J: Cellular background level of 8-oxo-7,8 dihydro-20-deoxyguanosine: An isotope based method to evaluate artefactual oxidation of DNA during its extraction and subsequent workup. Carcinogenesis 2002, 23:1911-1918

19. Arnaud J, Fortis I, Blachier S, Kia D, Favier A: Simultaneous determination of retinol, alpha-tocopherol and beta-carotene in serum by isocratic high-performance liquid chromatography. J Chromatogr 1991, 572:103-116

20. Abbas A, Lepelley M, Lechevrel M, Sichel F: Assessment of DHPLC usefulness in the genotyping of GSTP1 exon 5 SNP: comparison to the PCR-RFLP method. J Biochem Biophys Methods 2004, 59:121-126.

21. Hardie LJ, Briggs JA, Davidson LA, Allan JM, King RF, Williams GI, Wild CP: The effect of hOGG1 and glutathione peroxidase I genotypes and $3 p$ chromosomal loss on 8-hydroxydeoxyguanosine levels in lung cancer. Carcinogenesis 2000, 21:167-172.

22. Gackowski D, Kowalewski J, Siomek A, Olinski R: Oxidative DNA damage and antioxidant vitamin level: comparison among lung cancer patients, healthy smokers and nonsmokers. Int J Cancer 2005, 114:153-156.

23. Foksinski M, Gackowski D, Rozalski R, Siomek A, Guz J, Szpila A, Dziaman T, Olinski R: Effects of basal level of antioxidants on oxidative DNA damage in humans. Eur J Nutr 2007, 46:174-180. 
24. Calişkan-Can E, Firat $H$, Ardiç S, Simşek B, Torun M, Yardim-Akaydin S: Increased levels of 8-hydroxydeoxyguanosine and its relationship with lipid peroxidation and antioxidant vitamins in lung cancer. Clin Chem Lab Med 2008, 46:107-112.

25. Olmedilla B, Granado F, Southon S, Wright AJ, Blanco I, Gil-Martinez E, Berg H, Corridan B, Roussel AM, Chopra M, Thurnham DI: Serum concentrations of carotenoids and vitamins $A, E$, and $C$ in control subjects from five European countries. Br J Nutr 2001, 85:227-238.

26. Lee KF, Chung WY, Benzie IF: Urine 8-oxo-7,8-dihydro-2'-deoxyguanosine (8-oxodG), a specific marker of oxidative stress, using direct, isocratic LCMS/MS: Method evaluation and application in study of biological variation in healthy adults. Clin Chim Acta 2010, 411:416-422.

27. European Standards Committee on Urinary (DNA) Lesion Analysis, Evans MD, Olinski R, Loft S, Cooke MS: Toward consensus in the analysis of urinary 8-oxo-7,8-dihydro-2'-deoxyguanosine as a noninvasive biomarker of oxidative stress. Faseb J 2010, 24:1249-1260.

28. Valavanidis A, Vlachogianni T, Fiotakis C: 8-hydroxy-2' -deoxyguanosine (8OHdG): A critical biomarker of oxidative stress and carcinogenesis. $J$ Environ Sci Health C Environ Carcinog Ecotoxicol Rev 2009, 27:120-139.

29. Sajous L, Botta A, Sari-Minodier I: [Urinary 8-hydroxy-2'-deoxyguanosine: a biomarker of environmental oxidative stress?]. Ann Biol Clin (Paris) 2008, 66:19-29.

30. Loft S, Møller P, Cooke MS, Rozalski R, Olinski R: Antioxidant vitamins and cancer risk: is oxidative damage to DNA a relevant biomarker? Eur J Nutr 2008, 47:19-28.

31. Gackowski D, Banaszkiewicz Z, Rozalski R, Jawien A, Olinski R: Persistent oxidative stress in colorectal carcinoma patients. Int J Cancer 2002. 101:395-397.

32. Vulimiri SV, Wu X, Baer-Dubowska W, de Andrade M, Detry M, Spitz MR, DiGiovanni J: Analysis of aromatic DNA adducts and 7,8-dihydro-8-oxo2 -deoxyguanosine in lymphocyte DNA from a case-control study of lung cancer involving minority populations. Mol Carcinog 2000, 27:34-46.

33. Oltra AM, Carbonell F, Tormos C, Iradi A, Saez GT: Antioxidant enzyme activities and the production of MDA and 8-oxo-dG in chronic lymphocytic leukemia. Free Radic Biol Med 2001, 30:1286-1292.

34. Senturker S, Karahalil B, Inal M, Yilmaz H, Muslumanoglu H, Gedikoglu G, Dizdaroglu M: Oxidative DNA base damage and antioxidant enzyme levels in childhood acute lymphoblastic leukemia. FEBS Lett 1997, 416:286-290.

35. Boeing $H$, Dietrich $T$, Hoffmann $K$, Pischon T, Ferrari $P$, Lahmann $P H$, Boutron-Ruault MC, Clavel-Chapelon F, Allen N, Key T, Skeie G, Lund E, Olsen A, Tjonneland A, Overvad K, Jensen MK, Rohrmann S, Linseisen J, Trichopoulou A, Bamia C, Psaltopoulou T, Weinehall L, Johansson I, Sanchez MJ, Jakszyn P, Ardanaz E, Amiano P, Chirlaque MD, Quiros JR, Wirfalt E, Berglund G, Peeters PH, van Gils CH, Bueno-de-Mesquita HB, Buchner FL, Berrino F, Palli D, Sacerdote C, Tumino R, Panico S, Bingham S, Khaw KT, Slimani N, Norat T, Jenab M, Riboli E: Intake of fruits and vegetables and risk of cancer of the upper aero-digestive tract: the prospective EPIC-study. Cancer Causes Control 2006, 17:957-969.

36. Kasum CM, Jacobs DR Jr, Nicodemus K, Folsom AR: Dietary risk factors for upper aerodigestive tract cancers. Int J Cancer 2002, 99:267-272.

37. Sauvaget C, Nagano J, Allen N, Kodama K: Vegetable and fruit intake and stroke mortality in the Hiroshima/Nagasaki Life Span Study. Stroke 2003, 34:2355-2360.

38. McCall MR, Frei B: Can antioxidant vitamins materially reduce oxidative damage in humans? Free Radic Biol Med 1999, 26:1034-1053.

39. Faruque MO, Khan MR, Rahman MM, Ahmed F: Relationship between smoking and antioxidant nutrient status. Br J Nutr 1995, 73:625-632.

40. Bjelakovic G, Nikolova D, Gluud LL, Simonetti RG, Gluud C: Mortality in randomized trials of antioxidant supplements for primary and secondary prevention: systematic review and meta-analysis. JAMA 2007, 297:842-857, Erratum in: JAMA 2008, 299:765-766.

41. Møller P, Loft S: Dietary antioxidants and beneficial effect on oxidatively damaged DNA. Free Radic Biol Med 2006, 41:388-415.

42. Singh R, Sram RJ, Binkova B, Kalina I, Popov TA, Georgieva T, Garte S, Taioli E, Farmer PB: The relationship between biomarkers of oxidative DNA damage, polycyclic aromatic hydrocarbon DNA adducts, antioxidant status and genetic susceptibility following exposure to environmental air pollution in humans. Mutat Res 2007, 620:83-92.
43. Sram RJ, Farmer P, Singh R, Garte S, Kalina I, Popov TA, Binkova B, Ragin C, Taioli E: Effect of vitamin levels on biomarkers of exposure and oxidative damage-the EXPAH study. Mutat Res 2009, 672:129-134.

44. Wong RH, Yeh CY, Hsueh YM, Wang JD, Lei YC, Cheng TJ: Association of hepatitis virus infection, alcohol consumption and plasma vitamin $\mathrm{A}$ levels with urinary 8-hydroxydeoxyguanosine in chemical workers. Mutat Res 2003, 535:181-186.

45. Bianchini F, Elmståhl S, Martinez-Garciá C, van Kappel AL, Douki T, Cadet J, Ohshima H, Riboli E, Kaaks R: Oxidative DNA damage in human lymphocytes: correlations with plasma levels of alpha-tocopherol and carotenoids. Carcinogenesis 2000, 21:321-324.

46. Evans MD, Singh R, Mistry V, Farmer PB, Cooke MS: Analysis of urinary 8oxo-7,8-dihydro-2'-deoxyguanosine by liquid chromatography-tandem mass spectrometry. Methods Mol Biol 2010, 610:341-351.

47. Hatt L, Loft S, Risom L, Møller P, Sørensen M, Raaschou-Nielsen O, Overvad K, Tjønneland A, Vogel U: OGG1 expression and OGG1 Ser326Cys polymorphism and risk of lung cancer in a prospective study. Mutat Res 2008, 639:45-54.

48. Kondo S, Toyokuni S, Tanaka T, Hiai H, Onodera H, Kasai H, Imamura M: Overexpression of the hOGG1 gene and high 8-hydroxy-2'deoxyguanosine (8-OHdG) lyase activity in human colorectal carcinoma: regulation mechanism of the 8-OHdG level in DNA. Clin Cancer Res 2000, 6:1394-1400

49. Li D, Firozi PF, Zhang W, Shen J, DiGiovanni J, Lau S, Evans D, Friess H, Hassan M, Abbruzzese JL: DNA adducts, genetic polymorphisms, and Kras mutation in human pancreatic cancer. Mutat Res 2002, 513:37-48.

50. Loft S, Svoboda P, Kasai H, Tjønneland A, Vogel U, Møller P, Overvad K, Raaschou-Nielsen O: Prospective study of 8-oxo-7,8-dihydro-2'deoxyguanosine excretion and the risk of lung cancer. Carcinogenesis 2006, 27:1245-1250.

51. Elahi A, Zheng Z, Park J, Eyring K, McCaffrey T, Lazarus P: The human OGG1 DNA repair enzyme and its association with orolaryngeal cancer risk. Carcinogenesis 2002, 23:1229-1234.

52. Aka P, Mateuca R, Buchet JP, Thierens H, Kirsch-Volders M: Are genetic polymorphisms in OGG1, XRCC1 and XRCC3 genes predictive for the DNA strand break repair phenotype and genotoxicity in workers exposed to low dose ionising radiations? Mutat Res 2004, 556:169-181.

53. Dherin C, Radicella JP, Dizdaroglu M, Boiteux S: Excision of oxidatively damaged DNA bases by the human alpha-hOgg1 protein and the polymorphic alpha-hOgg1(Ser326Cys) protein which is frequently found in human populations. Nucleic Acids Res 1999, 27:4001-4007.

54. Park YJ, Choi EY, Choi JY, Park JG, You HJ, Chung MH: Genetic changes of hOGG1 and the activity of oh8Gua glycosylase in colon cancer. Eur J Cancer 2001, 37:340-346.

55. Boiteux S, Radicella JP: The human OGG1 gene: structure, functions, and its implication in the process of carcinogenesis. Arch Biochem Biophys 2000, 377:1-8.

56. Cho EY, Hildesheim A, Chen CJ, Chen IH, Mittl BF, Levine PH, Liu MY, Chen JY, Brinton LA, Cheng YJ, Yang CS: Nasopharyngeal carcinoma and genetic polymorphisms of DNA repair enzymes XRCC1 and hOGG1. Cancer Epidemiol Biomarkers Prev 2003, 12:1100-1104.

57. Görgens H, Müller A, Krüger S, Kuhlisch E, König IR, Ziegler A, Schackert HK, Eckelt U: Analysis of the base excision repair genes MTH1, OGG1 and MUTYH in patients with squamous oral carcinomas. Oral Oncol 2007, 43:791-795.

58. Tse D, Zhai R, Zhou W, Heist RS, Asomaning K, Su L, Lynch TJ, Wain JC, Christiani DC, Liu G: Polymorphisms of the NER pathway genes, ERCC1 and XPD are associated with esophageal adenocarcinoma risk. Cancer Causes Control 2008, 19:1077-1083.

59. Li H, Hao X, Zhang W, Wei Q, Chen K: The hOGG1 Ser326Cys polymorphism and lung cancer risk: a meta-analysis. Cancer Epidemiol Biomarkers Prev 2008, 17:1739-1745.

60. Garte S, Taioli E, Raimondi S, Paracchini V, Binkova B, Sram RJ, Kalina I, Popov TA, Singh R, Farmer PB: Effects of metabolic genotypes on intermediary biomarkers in subjects exposed to PAHS: results from the EXPAH study. Mutat Res 2007, 620:7-15.

61. Marczynski B, Rihs HP, Rossbach B, Hölzer J, Angerer J, Scherenberg M, Hoffmann G, Brüning T, Wilhelm M: Analysis of 8-oxo-7,8-dihydro-2'deoxyguanosine and DNA strand breaks in white blood cells of occupationally exposed workers: comparison with ambient monitoring, 
urinary metabolites and enzyme polymorphisms. Carcinogenesis 2002, 23:273-281.

62. Sørensen M, Skov H, Autrup H, Hertel O, Loft S: Urban benzene exposure and oxidative DNA damage: influence of genetic polymorphisms in metabolism genes. Sci Total Environ 2003, 309:69-80

63. Sørensen M, Autrup H, Hertel O, Wallin H, Knudsen LE, Loft S: Personal exposure to PM2.5 and biomarkers of DNA damage. Cancer Epidemiol Biomarkers Prev 2003, 12:191-196.

64. Dennog C, Gedik C, Wood S, Speit G: Analysis of oxidative DNA damage and HPRT mutations in humans after hyperbaric oxygen treatment. Mutat Res 1999, 431:351-359.

doi:10.1186/1756-9966-29-157

Cite this article as: Lagadu et al:: 8-oxo-7,8-dihydro-2'-deoxyguanosine as a biomarker of oxidative damage in oesophageal cancer patients: lack of association with antioxidant vitamins and polymorphism of hOGG1 and GST. Journal of Experimental \& Clinical Cancer Research 2010 29:157.

Submit your next manuscript to BioMed Central and take full advantage of:

- Convenient online submission

- Thorough peer review

- No space constraints or color figure charges

- Immediate publication on acceptance

- Inclusion in PubMed, CAS, Scopus and Google Scholar

- Research which is freely available for redistribution

Submit your manuscript at www.biomedcentral.com/submit 